\title{
Research Article \\ Heart Rate Index Corrects for The Limitations of Heart Rate Assessment of Occupational Physical Activity
}

\author{
John Wicks*(iD, Kryss McKenna, Sharyn McSorley, David Craig \\ Department of Rehabilitation, Robina Hospital, Robina, Queensland, Australia
}

\author{
Article Information \\ History: \\ Received: July 18, 2018 \\ Accepted: October 18, 2018 \\ Published: October 31, 2018 \\ Keywords: \\ Energy expenditure \\ Exercise \\ Heart rate index \\ Occupational physical activity \\ Smoking
}

\begin{abstract}
Objectives: Recording devices relying solely on heart rate (HR) are not considered accurate enough for measurement of energy expenditure of occupational physical activity (OPA) and leisure time physical activity (LTPA), due to factors which modulate the heart rate-oxygen uptake relationship such as smoking and cardiorespiratory fitness. This study used HR index which corrects for the effect of smoking and cardiorespiratory fitness on HR, to estimate the exercise intensity of occupational activity and determine whether smoking and exercise habits influenced work performance.
\end{abstract}

Methods: A total of 176 hospital employees from five occupational categories (sedentary, ambulant-sedentary, light, moderate and heavy) wore an R-R interval recorder during a standard days' work (mean recording time $6.4 \pm 0.9$ hours). From HR histogram analysis, resting, mean and peak HRs and mean and peak indices were determined, with oxygen uptake, expressed as metabolic equivalents (METs), being estimated from the HR index equation.

Results: Mean index, but not mean HR, showed a progressive increase from sedentary to heavy occupational categories, with the estimated mean MET levels for the entire work period ranging from 2.0 to 3.1 METs for males and 1.9 to 2.7 METs for females. Peak index tended to parallel the increase in mean index. Smoking had the effect of increasing resting HR by 7.5 beats. $\mathrm{min}^{-1}$ with regular exercise participation lowering resting HR by 11.0 beats. $\mathrm{min}^{-1}$, these two lifestyle factors limiting the accuracy of mean $\mathrm{HR}$ for determining exercise intensity

Conclusions: Smoking and exercise habit significantly impact on resting, mean and peak HR during OPA and may influence work performance. The use of HR index as opposed to HR may improve the analysis of OPA and provide a simple method for estimation of both exercise intensity and energy expenditure.

\section{INTRODUCTION}

HR (heart rate) is the simplest physiological variable to measure for estimation of exercise intensity (EI) and energy expenditure (EE). The recent rapid development of wearable technology incorporating HR and motion sensors facilitates measurement of EE over extended periods of time and this information may assist individuals in making healthy lifestyle changes.

In both a home and work setting, technology has resulted in decreased levels of physical activity. Within manufacturing industries, automation, mechanisation and robotics have

*Correspondence: John Richard Wicks, Robina Hospital, 2 Bayberry Lane, Department of Rehabilitation, Robina Hospital, Robina, Queensland, Australia E-mail address: john.wicks@health.qld.gov.au reduced the physical demands of OPA resulting in increased sedentary behaviour [1] considered to be associated with an adverse health risk [2].

The use of HR to estimate EI is reliant on the linear relationship of $\mathrm{HR}$ to oxygen uptake $\left(\mathrm{VO}_{2}\right)$ [3]. However cardiorespiratory fitness (CRF) and tobacco smoking will influence this relationship [3] and to use HR without individual calibration of the $\mathrm{HR}-\mathrm{VO}_{2}$ limits its use. When using $\mathrm{HR}$ to estimate EE at near sedentary levels of activity where the $\mathrm{HR}-\mathrm{VO}_{2}$ relationship is less precise, the flex $\mathrm{HR}\left(\mathrm{HR}_{\mathrm{flex}}\right)$ method is frequently used [4]. Individual $\mathrm{HR}-\mathrm{VO}_{2}$ calibration is a prerequisite and in defining $\mathrm{HR}_{\text {flex }}$ as the average of the highest resting $\mathrm{HR}\left(\mathrm{HR}_{\text {rest }}\right)$ and the lowest level of activity $\mathrm{HR}\left(\mathrm{HR}_{\text {activity }}\right)$, time spent below $\mathrm{HR}_{\text {flex }}$ is considered to be 1 MET (1 MET being the $\mathrm{VO}_{2}$ at rest, namely $3.5 \mathrm{~mL}$ $\left.\mathrm{O}_{2} \cdot \mathrm{kg}^{-1} \cdot \mathrm{min}^{-1}\right)[5]$.

The ability to correct for variables such as CRF and smokterms of the Creative Commons Attribution License (http://creativecommons.org/licenses/by/4.0/), which permits unrestricted use, distribution, and reproduction in any medium, provided the original work is properly cited. 


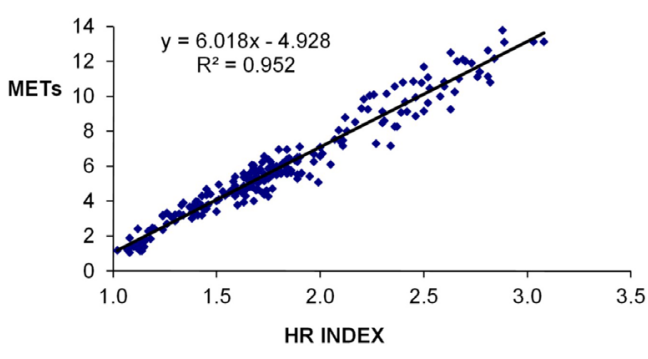

Figure 1. Linear regression of plot of HR index equation.

Linear regression analysis from data $(n=220)$ derived from 60 studies with the HR index equation simplified to METs $=6 \times \mathrm{HR}$ index -5 .

ing that influence the $\mathrm{HR}-\mathrm{VO}_{2}$ relationship was demonstrated in the recently published HR index (HRI) equation [6]. The equation relies on two variables to estimate EE, namely $\mathrm{HR}_{\text {rest }}$ and $\mathrm{HR}_{\text {activity }}$ the equation being METs $=6 \times \mathrm{HRI}-$ 5, with HRI being $\mathrm{HR}_{\text {activity }} / \mathrm{HR}_{\text {rest }}$. The equation was determined from data from 60 studies involving 11,257 subjects and the relation of HRI to $\mathrm{VO}_{2}$ (expressed as METs) was shown to be independent of common factors such as age, gender, CRF, smoking and beta-blocker effect. The original data are shown in Figure 1.

The utility of this equation is that it provides a simple independent surrogate method for estimating $\mathrm{VO}_{2}$ using only two HR measurements, $\mathrm{HR}_{\text {rest }}$ and $\mathrm{HR}_{\text {activity }}$, either submaximal or maximal. Whilst there has been no analysis to date to determine its predictive accuracy for individual assessment of $\mathrm{VO}_{2}$, a recent study used HRI to assess EE in soldiers performing loaded runs from $10-20 \mathrm{~km}$ in full combat equipment in a field environment [7]. An extremely close agreement was found between the use of HRI to assess EE when compared with equations previously validated by indirect calorimetry. The study is important for at sustained high work level ( $>50-75 \%$ of maximum $\mathrm{VO}_{2}$ ), "cardiovascular drift" may occur [8]. This altered $\mathrm{HR}-\mathrm{VO}_{2}$ relationship is largely attributed to a reduction in stroke volume due to inadequate fluid replacement during extended work, particularly in work conditions involving high levels of ambient temperature and humidity $[8,9]$.

With the world-wide trend towards increasing obesity [10], measurement of the EE of both OPA and LTPA is paramount for determining the potential contribution of decreased EE to obesity. In using both HR and HRI the impact of both smoking and exercise habits on OPA was assessed.

\section{METHODS}

\section{HR Data Acquisition Device}

A self-contained microprocessor-based HR recording device designed in 1981 by one of the authors (D.C.) in the Bioengineering Department of Greenslopes Hospital was

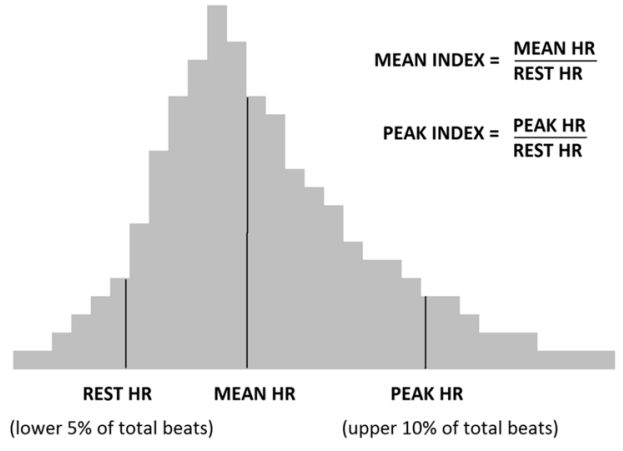

Figure 2. Schematic of histogram construction

The horizontal axis represents range of heart rate, the vertical axis representing the number of beats in each HR bin. Mean and peak indices are defined as mean and peak HRs divided by resting HR.

used to acquire HR histogram data during extended daily activity by hospital workers [11] . Using a 3-lead system, the device continually monitors the R-R interval. The effective $\mathrm{HR}$ for each beat is determined with each beat being placed in a HR histogram bin ( 5 beats. $\mathrm{min}^{-1}$ width), the range of recorded HR being from 35 to 175 beats $\mathrm{min}^{-1}$ (a total of 30 bins). On completion of the recording period stored data was downloaded to a computer. Data obtained from the microprocessor included total time, total number of heart beats and bin totals of heart beats.

\section{Proposed Calculation of HR Indices for EI Assessment}

In the initial development of the HR histogram recorder at the Greenslopes Hospital, staff during a standard work period were assessed with recordings being done over a 4-8 hour period. By incorporating rest periods of at least 20-30 minutes (during refreshment and lunch breaks), data acquired by the HR histogram recorder showed that the HR delimiting the lower $5 \%$ of beats corresponded to a period of approximately 30 minutes and was designated $\mathrm{HR}_{\text {rest }}$. The HR delimiting the upper $10 \%$ of beats within the HR histogram corresponded to approximately 30 minutes and was designated peak $\mathrm{HR}\left(\mathrm{HR}_{\text {peak }}\right)$.

To use relative HR as a basis of EI assessment, two indices were calculated, namely mean index $\left(\mathrm{HRI}_{\text {mean }}\right)=\mathrm{HR}_{\text {mean }}$ ' $\mathrm{HR}_{\text {rest }}$ and peak index $\left(\mathrm{HRI}_{\text {peak }}\right)=\mathrm{HR}_{\text {peak }} / \mathrm{HR}_{\text {rest }}$ (Figure 2).

From the HRI $\mathrm{Hean}_{\text {ma }}$ and $\mathrm{HR}_{\text {peak }}$ of the five occupational groups, an estimation of EI as METs was determined from the HRI equation. The values of HR, HR indices and estimated EI represent mean values for the total recording period.

\section{Subjects}

Ethics approval for the study was obtained from the Greenslopes Repatriation Hospital Human Research Ethics Committee. Written informed consent was obtained from all participants, the one subject aged 17 years providing written consent from her parents. 
From a total of 190 individual subject recordings, 14 were excluded as unsatisfactory, the main reasons being unsatisfactory lead contact or inadequate length of recording. The remaining $176 \mathrm{HR}$ histogram recordings from hospital staff (93 females and 83 males) with an age range from 17 to 60 years, from 5 different occupational categories were included in the present study. Subjects wore the recording device continuously for one work period, the mean recording time being $6.4 \pm 0.9$ hours. During the recording period subjects were advised to have at least 20-30 minutes of rest during refreshment or lunch breaks to allow determination of $\mathrm{HR}_{\text {rest }}$. The contact time required with the subject for personal data acquisition was done prior to the recording period.

Determination of occupational category was performed by interview with an occupational therapist, where a subject's job description and the range of activities undertaken during a typical working day were evaluated. An onsite inspection of the hospital facility where subjects worked assisted with estimating the likely MET levels associated with activities performed. The 5 work categories used for this study were 1 . Sedentary (very inactive) - sitting most of the day e.g. secretaries, telephonists 2. Ambulant-sedentary (fairly inactive) - sitting for most of the day, short periods of standing and walking e.g. paramedical personnel, supervisors 3. Light (somewhat active) - some sitting, moderate amounts of standing and walking e.g. nursing staff, electricians, kitchen hands 4. Moderate (fairly active) - intermittent periods of lifting, carrying, stair climbing, constant walking throughout day e.g. laundry workers, painters, carpenters and 5. Heavy (very active) - heavy or constant work for most of the day, using heavy tools, involving lifting, carrying, pushing, pulling, stair climbing e.g. builders, porters, plumbers, storemen.

In the voluntary recruitment of staff an attempt was made to have similar numbers of subjects in the 5 occupational categories. The categories of light, moderate and heavy were chosen to suit the range of work undertaken by subjects within this hospital and were not based on any particular industrial or international classification. The inclusion of the ambulant-sedentary was based on observation of Lange-Andersen who noted that amongst sedentary workers, a significant number undertook incidental physical activity which impacted on total EE [12].

Personal information obtained included age, sex, height, weight, smoking habit, exercise participation and medication. No subjects were on beta blocker therapy and all were in sinus rhythm as shown by prior ECG screening. Subjects were classed as either smokers or non-smokers. In assessing LTPA for both recreational exercise and sport, the type (estimated MET intensity), frequency and duration of activities were noted and a total MET-minutes per week was calculated for each subject based on MET levels from a compendium of activities sourced from published data at the time this study was undertaken [13]. In analysing the effect of CRF within this study, subjects were classed as either exercisers ( $\mathrm{n}$ $=95)$ or non-exercisers $(n=81)$, with non-exercisers stating that they did not participate in any regular physical activity.

\section{Statistical Analysis}

Minitab Student release 12 (Minitab Inc, State College, PA, USA) was utilized for statistical analysis. Categorical variables are expressed as numbers and percentages with continuous variables expressed as mean \pm standard deviation. Student's paired t-test was used to compare group characteristics. The distribution of behavioural characteristics within occupational groups was determined by chi square test.

\section{RESULTS}

Subjects ranged in age from 17-60 years, males 35.9 \pm 11.2 $($ mean \pm SD), females $33.9 \pm 10.2$ years. The BMI for males was $24.9 \pm 3.3$ and for females $22.1 \pm 3.2$. At the time of the study in 1984, 39 males (46\%) and 28 females (30\%) smoked with rates of smoking in Australia at that time being reported as $40 \%$ and $29 \%$ for males and females respectively [14]. A total of 81 (46\%) subjects stated that they engaged in no regular exercise or sport. Summary data is shown in Table 1A (males) and 1B (females).

For both sexes a gradation in HRI ${ }_{\text {mean }}$ is seen from the lowest to the highest intensity occupational category. For males, the HRI for sedentary workers was 1.19 (estimated 2.04 METs) increasing to 1.37 (estimated 3.06 METs) for the heavy category. For females, comparable values of $\mathrm{HRI}_{\text {mean }}$ were 1.17 (estimated 1.90 METs) increasing to 1.30 (estimated 2.67 METs). If $\mathrm{HR}_{\text {mean }}$ is considered for both sexes, a gradation for the five occupational categories is not seen. In fact, the $\mathrm{HR}_{\text {mean }}$ of 91.0 beats. $\mathrm{min}^{-1}$ for males in the heavy work category is similar to the ambulant sedentary category (89.6 beats $\cdot \mathrm{min}^{-1}$ ) and light category (90.2 beats. $\left.\mathrm{min}^{-1}\right)$ and less than that of moderate category $\left(97.2\right.$ beats $\left.\cdot \mathrm{min}^{-1}\right)$. However, once relative HR in the form of HR indices is considered, the low $\mathrm{HR}_{\text {rest }}$ observed in the heaviest work category impacts on $\mathrm{HRI}_{\text {mean }}$ allowing for better discrimination of work intensity. For females $\mathrm{HR}_{\text {mean }}$ was quite similar for the five occupational categories with the sedentary and heavy groups having virtually identical $\mathrm{HR}_{\text {mean }}$, sedentary 93.3 beats. min $^{-1}$ and heavy 93.2 beats. $\mathrm{min}^{-1}$. However, the gradation in work intensity was again consistently shown by use of HRI A similar gradation by occupational category for $\mathrm{HRI}_{\text {peak }}$ is seen for both sexes which suggests that as HRI mean $_{\text {increases, }}$ HRI $_{\text {peak }}$ tends to parallel this change. Male subjects in the heavy work category had both a higher HRI mean $_{\text {and }}$ anI than females; HRI ${ }_{\text {mean }}$ males, 1.37 and HRI ${ }_{\text {mean }}$ females 1.30 $(\mathrm{p}=0.009), \mathrm{HRI}_{\text {peak }}$ males, 1.73 and females, $\mathrm{HRI}_{\text {peak }} 1.59$ $(\mathrm{p}=0.004)$.

To assess the individual effect of smoking and exercise participation on $\mathrm{HR}_{\text {rest }}$ group data for males and females were combined. The group mean $\mathrm{HR}_{\text {rest }}$ for smokers ( $\mathrm{n}$ = 67) was 78.8 beats $\cdot \mathrm{min}^{-1}$ and 71.3 beats $\cdot \mathrm{min}^{-1}$ for nonsmokers $(\mathrm{n}=109)$, a difference of 7.5 beats $\cdot \mathrm{min}^{-1}(\mathrm{p}<0.001)$. The group mean $\mathrm{HR}_{\text {rest }}$ for exercisers $(\mathrm{n}=95)$ was 69.1 beats $\cdot \min ^{-1}$ and 80.1 beats $\cdot \min ^{-1}$ for non-exercisers $(n=81)$, a difference of 11.0 beats $\cdot \mathrm{min}^{-1}(\mathrm{p}<0.001)$. When considered by gender, similar differences were observed between males 
Table 1. Physical characteristics, heart rates (rest, mean and peak) and derived indices (mean and peak) for males and females in 5 occupational categories.

\begin{tabular}{|c|c|c|c|c|c|}
\hline Category & Sedentary & Amb-sed. & Light & Moderate & Heavy \\
\hline \multicolumn{6}{|l|}{ A. Males } \\
\hline $\mathrm{N}$ & 15 & 16 & 18 & 18 & 16 \\
\hline Age (years) & $39.7 \pm 13.0$ & $36.2 \pm 11.8$ & $35.3 \pm 11.4$ & $35.5 \pm 11.3$ & $33.5 \pm 8.7$ \\
\hline BMI & $25.9 \pm 3.5$ & $25.5 \pm 4.0$ & $24.0 \pm 3.1$ & $25.8 \pm 2.7$ & $24.7 \pm 3.2$ \\
\hline Tobacco & $4(27 \%)$ & $6(38 \%)$ & $10(56 \%)$ & $9(50 \%)$ & $10(63 \%)$ \\
\hline Exercise & $9(60 \%)$ & $9(56 \%)$ & $6(33 \%)$ & $7(39 \%)$ & $10(63 \%)$ \\
\hline $\mathrm{HR}_{\text {rest }}$ (beats $\cdot \min ^{-1}$ ) & $72.5 \pm 8.9$ & $75.4 \pm 10.9$ & $73.3 \pm 9.8$ & $77.3 \pm 10.7$ & $66.7 \pm 14.1$ \\
\hline $\mathrm{HR}_{\text {mean }}$ (beats $\cdot \mathrm{min}^{-1}$ ) & $86.2 \pm 8.4$ & $89.6 \pm 1.7$ & $90.2 \pm 12.6$ & $97.2 \pm 13.1$ & $91.0 \pm 18.4$ \\
\hline $\mathrm{HR}_{\text {peak }}$ (beats· $\min ^{-1}$ ) & $97.3 \pm 8.8$ & $101.4 \pm 11.8$ & $104.3 \pm 14.0$ & $117.5 \pm 12.6$ & $114.4 \pm 22.6$ \\
\hline $\mathrm{HRI}_{\text {mean }}$ & $1.19 \pm 0.06$ & $1.19 \pm 0.03$ & $1.23 \pm 0.03$ & $1.26 \pm 0.02$ & $1.37 \pm 0.10$ \\
\hline $\mathrm{HRI}_{\text {peak }}$ & $1.35 \pm 0.11$ & $1.35 \pm 0.05$ & $1.42 \pm 0.04$ & $1.53 \pm 0.12$ & $1.73 \pm 0.18$ \\
\hline METs (HRI $\left.I_{\text {mean }}\right)$ & $2.04 \pm 0.39$ & $2.03 \pm 0.16$ & $2.26 \pm 0.17$ & $2.42 \pm 0.11$ & $3.06 \pm 0.60$ \\
\hline METs (HRI peak $)$ & $3.10 \pm 0.67$ & $3.11 \pm 0.30$ & $3.54 \pm 0.27$ & $4.18 \pm 0.71$ & $5.38 \pm 1.06$ \\
\hline \multicolumn{6}{|l|}{ B. Females } \\
\hline $\mathrm{N}$ & 18 & 19 & 19 & 18 & 19 \\
\hline Age (years) & $36.7 \pm 13.0$ & $33.2 \pm 11.8$ & $33.9 \pm 11.4$ & $32.4 \pm 11.3$ & $33.5 \pm 8.7$ \\
\hline BMI & $22.6 \pm 3.5$ & $22.7 \pm 4.0$ & $22.8 \pm 3.1$ & $21.2 \pm 2.7$ & $22.2 \pm 3.2$ \\
\hline Tobacco & $8(44 \%)$ & $4(21 \%)$ & $7(37 \%)$ & $4(22 \%)$ & $5(26 \%)$ \\
\hline Exercise & $6(33 \%)$ & $13(68 \%)$ & $12(63 \%)$ & $9(58 \%)$ & $14(74 \%)$ \\
\hline $\mathrm{HR}_{\text {rest }}\left(\right.$ beats. $\left.\min ^{-1}\right)$ & $80.3 \pm 7.1$ & $71.5 \pm 12.5$ & $75.9 \pm 9.2$ & $75.9 \pm 5.1$ & $71.9 \pm 8.3$ \\
\hline $\mathrm{HR}_{\text {mean }}\left(\right.$ beats. $\mathrm{min}^{-1}$ ) & $93.3 \pm 6.7$ & $86.2 \pm 11.5$ & $92.0 \pm 10.5$ & $93.7 \pm 6.4$ & $93.2 \pm 9.3$ \\
\hline $\mathrm{HR}_{\text {peak }}\left(\right.$ beats $\cdot \mathrm{min}^{-1}$ ) & $104.0 \pm 7.2$ & $98.8 \pm 10.2$ & $104.8 \pm 12.1$ & $109.9 \pm 7.6$ & $113.5 \pm 9.8$ \\
\hline $\mathrm{HRI}_{\text {mean }}$ & $1.17 \pm 0.05$ & $1.22 \pm 0.06$ & $1.21 \pm 0.05$ & $1.23 \pm 0.02$ & $1.30 \pm 0.04$ \\
\hline $\mathrm{HRI}_{\text {peak }}$ & $1.30 \pm 0.09$ & $1.40 \pm 0.13$ & $1.38 \pm 0.06$ & $1.45 \pm 0.06$ & $1.59 \pm 0.09$ \\
\hline $\operatorname{METs}\left(\mathrm{HRI}_{\text {mean }}\right)$ & $1.90 \pm 0.33$ & $2.20 \pm 0.39$ & $2.18 \pm 0.31$ & $2.28 \pm 0.11$ & $2.67 \pm 0.25$ \\
\hline METs $\left(\mathrm{HRI}_{\text {peak }}\right)$ & $2.81 \pm 0.56$ & $3.41 \pm 0.79$ & $3.30 \pm 0.37$ & $3.69 \pm 0.37$ & $4.51 \pm 0.54$ \\
\hline
\end{tabular}

Results expressed as mean \pm SD for age, BMI and HR data. Smoking and exercise participation are shown as number of participants (percentage in brackets). The estimated MET levels associated with mean index $\left(\mathrm{HRI}_{\text {mean }}\right)$ and peak index $\left(\mathrm{HRI}_{\text {peak }}\right)$ are derived from the HRI equation.

Table 2. Resting HR (quartile mean \pm SD and HR range) shown for quartiles (Q1-Q4) with smoking (S) and exercise habit (E) shown as number (percentage in brackets) within each quartile.

\begin{tabular}{|c|c|c|c|c|}
\hline & Q1 & Q2 & Q3 & Q4 \\
\hline Number & 44 & 44 & 44 & 44 \\
\hline $\mathrm{HR}_{\text {rest }}\left(\right.$ beats $\left.\cdot \mathrm{min}^{-1}\right)$ mean $\pm \mathrm{SD}$ & $60.2 \pm 5.7$ & $71.5 \pm 1.7$ & $78.5 \pm 2.3$ & $86.3 \pm 3.6$ \\
\hline $\mathrm{HR}_{\text {rest }}$ (beats·min ${ }^{-1}$ ) range & $40-68$ & 69-74 & 75-81 & 81-95 \\
\hline $\mathrm{E}+(\%)$ & $37(84 \%)$ & $36(82 \%)$ & $15(34 \%)$ & $8(18 \%)$ \\
\hline E- (\%) & $7(16 \%)$ & $8(18 \%)$ & $29(66 \%)$ & $36(82 \%)$ \\
\hline $\mathrm{S}+(\%)$ & $7(16 \%)$ & $11(25 \%)$ & $19(43 \%)$ & $30(68 \%)$ \\
\hline S- (\%) & $37(84 \%)$ & $33(75 \%)$ & $25(57 \%)$ & $14(32 \%)$ \\
\hline
\end{tabular}

Smoking and exercise participation shown as E+, exercise participation; E-, no exercise; S+, smoking; S-, non-smoking with numbers in each category (percentage in brackets).

and females.

The effect of smoking and exercise habit on $\mathrm{HR}_{\text {rest }}$ is shown in Table 2 where $\mathrm{HR}_{\text {rest }}$ is displayed in quartiles. In quartile $1\left(\mathrm{HR}_{\text {rest }} 60.2\right.$ beats $\left.\cdot \mathrm{min}^{-1}\right), 84 \%$ had a regular exercise habit and $84 \%$ were non-smokers. A gradient of a decreasing rate of exercise habit and increasing rate of smoking is seen from quartile 1 to quartile 4 , such that in quartile $4{\text { ( } \mathrm{HR}_{\text {rest }}} 86.3$ beats $\cdot \mathrm{min}^{-1}$ ) only $18 \%$ had a regular exercise habit and only $32 \%$ were non-smokers.

The study design attempted to discriminate between sedentary and ambulant-sedentary categories assuming that self-reported activity would identify individuals who undertook a higher level of incidental activity. However, a similar $\mathrm{HRI}_{\text {mean }}$ for sedentary and ambulant-sedentary categories was observed for males, the HRI mean $_{\text {for }}$ both groups being 1.19 (estimated 2.0 METs). For females, the corresponding $\mathrm{HRI}_{\text {mean }}$ values for sedentary and ambulantsedentary were 1.17 and 1.22 (estimated 1.9 and 2.2 METs respectively, $p=0.016$ ). To identify subjects within the sedentary and ambulant-sedentary groups with higher levels of either incidental or work-related activity, a separate analysis of the combined group of sedentary and ambulantsedentary $(\mathrm{S}+\mathrm{AS})$ was undertaken. The intention was to discern the effect of smoking and exercise habit on HRI ${ }_{\text {mean }}$. Data for both males and females for the two groups were pooled and divided into two roughly equal groups, a low 
range $\mathrm{HRI}_{\text {mean }}$ (males 1.14-1.18, average $\mathrm{HRI}_{\text {mean }} 1.16$ ) and females $\left(1.10-1.17\right.$, average $\left.\mathrm{HRI}_{\text {mean }} 1.14\right)$ and a high range

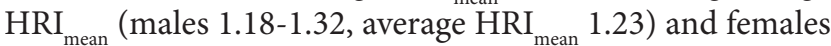
(1.18-1.34, average HRI $\left.I_{\text {mean }} 1.24\right)$. Subject characteristics for both sexes are shown in Table 3.

For both sexes, the observed differences of age and BMI between the two activity groups were not significant. However, for males the $\mathrm{HR}_{\text {rest }}$ and the $\mathrm{HR}_{\text {mean }}$ for the least active $S+A S$ were significantly higher than the more active $\mathrm{S}+\mathrm{AS}(\mathrm{p}<0.001$ and $\mathrm{p}=0.009$, respectively); the HR profile for least and most active S+AS females was similar to the males $\left(\mathrm{HR}_{\text {rest' }}, \mathrm{p}<0.001\right.$ and $\left.\mathrm{HR}_{\text {mean }}, \mathrm{p}<0.001\right)$.

Whilst the HR results for low and high range A+AS for both males and females were unexpected, this observation is likely related to the smoking and exercise habits of both groups. For males, $62 \%$ of the least active S+AS smoked compared with $0 \%$ for the more active $S+A S(p<0.001)$. For females, $58 \%$ of the least active $\mathrm{S}+\mathrm{AS}$ smoked compared with $6 \%$ of the more active $S+A S(p=0.001)$. Fewer males in the least active $\mathrm{S}+\mathrm{AS}$ exercised when compared with the more active $S+A S, 37 \%$ and $80 \%$ respectively $(\mathrm{p}=0.029)$. For females, the least active S+AS exercise participation rate was $26 \%$ compared with the more active $\mathrm{S}+\mathrm{AS}$ exercise participation rate of $74 \%(\mathrm{p}=0.003)$.

\section{DISCUSSION}

The purpose of this study was to examine the individual effects of smoking and a regular exercise habit on HR and therefore HRI, and the ability of HRI to determine activity patterns of both sedentary and manual workers within a large metropolitan hospital. Though the concept of displaying occupational HR in the form of a histogram has previously been used, there has been no published method of processing histogram data to estimate EI in METs [1517]. The HRI method used in this study simplifies the use of HR to determine EI and estimate EE for a defined work period. However, at the time of the study, the limited memory capacity of the R-R interval recorder did not allow for estimates of accumulated time above defined MET thresholds e.g. light intensity $1.6-2.9$ METs, moderate intensity 3.0 - 5.9 METs and heavy intensity $>6$ METs [5].

For both male and female occupational categories, $\mathrm{HR}_{\text {mean }}$ did not show any consistent trend to suggest increasing work intensity in progressing from sedentary to manual work categories, being influenced by exercise participation and smoking rates within occupational categories. However, with the use of $\mathrm{HRI}_{\text {mean }}$, the trend of increasing work intensity was clearly apparent for both males and females across the five occupational categories (Tables 1A Males, 1B Females). The correction resulting from the use of HRI accounts for (and negates) the influence of the two common factors of smoking and CRF on the physiological modulation of HR. Other factors that can affect HR response include extreme environmental work conditions (heat, cold, high humidity) but were not relevant to the work conditions observed within this study at this hospital [9].

The significant difference in $\mathrm{HR}_{\text {rest }}$ observed in this study between smoking and non-smoking workers of 7.5

Table 3. Characteristics of males and females for combined categories - sedentary and ambulant-sedentary.

\begin{tabular}{|c|c|c|c|}
\hline $\mathrm{HRI}_{\text {mean }}$ range & Low range & High range & $P$ value \\
\hline A. Males & $(1.14-1.18)$ & $(1.19-1.32)$ & \\
\hline Number & 16 & 15 & \\
\hline Average $\mathrm{HRI}_{\text {mean }}$ & $1.16 \pm 0.01$ & $1.23 \pm 0.05$ & \\
\hline Age (years) & $40.8 \pm 14.2$ & $34.7 \pm 9.4$ & 0.173 \\
\hline BMI & $26.6 \pm 4.0$ & $24.7 \pm 3.3$ & 0.153 \\
\hline $\mathrm{HR}_{\text {rest }}$ (beats. $\min ^{-1}$ ) & $79.7 \pm 9.0$ & $67.9 \pm 6.9$ & $<0.001$ \\
\hline $\mathrm{HR}_{\text {rest }}$ (beats $\cdot \min ^{-1}$ ) & $92.4 \pm 10.8$ & $83.2 \pm 7.2$ & 0.009 \\
\hline $\mathrm{HR}_{\text {rest }}$ (beats $\cdot \min ^{-1}$ ) & $103 \pm 11.9$ & $95.6 \pm 7.3$ & 0.046 \\
\hline $\mathrm{S}+(\%)$ & $10(62 \%)$ & $0(0 \%)$ & $<0.001$ \\
\hline $\mathrm{E}+(\%)$ & $6(37 \%)$ & $12(80 \%)$ & 0.029 \\
\hline Ambulant-sedentary(\%) & $7(44 \%)$ & $9(56 \%)$ & 0.479 \\
\hline B. Females & $(1.10-1.17)$ & $(1.18-1.34)$ & \\
\hline Number & 19 & 18 & \\
\hline Average $\mathrm{HRI}_{\text {mean }}$ & $1.14 \pm 0.02$ & $1.24 \pm 0.05$ & \\
\hline Age (years) & $38.2 \pm 10.8$ & $31.4 \pm 10.3$ & 0.061 \\
\hline BMI & $23.5 \pm 4.0$ & $21.9 \pm 2.5$ & 0.154 \\
\hline $\mathrm{HR}_{\text {rest }}\left(\right.$ beats $\cdot \mathrm{min}^{-1}$ ) & $83.2 \pm 6.6$ & $67.9 \pm 9.3$ & $<0.001$ \\
\hline $\mathrm{HR}_{\text {rest }}\left(\right.$ beats $\left.\cdot \mathrm{min}^{-1}\right)$ & $95.0 \pm 7.6$ & $84.1 \pm 9.3$ & $<0.001$ \\
\hline $\mathrm{HR}_{\text {rest }}\left(\right.$ beats $\cdot \mathrm{min}^{-1}$ ) & $104.6 \pm 8.1$ & $97.9 \pm 9.1$ & 0.025 \\
\hline $\mathrm{S}+\%$ & $11(58 \%)$ & $1(6 \%)$ & 0.001 \\
\hline $\mathrm{E}+\%$ & $5(26 \%)$ & $14(74 \%)$ & 0.003 \\
\hline Ambulant-sedentary\% & $7(37 \%)$ & $12(63 \%)$ & 0.103 \\
\hline
\end{tabular}

Results expressed as mean \pm SD for age, $\mathrm{BMI}_{\mathrm{HR}_{\text {rest }}}$, $\mathrm{HR}_{\text {mean }}$, and $\mathrm{HR}_{\text {peak }}$. Smoking, S+; exercise participation, E+; and ambulant-sedentary are shown

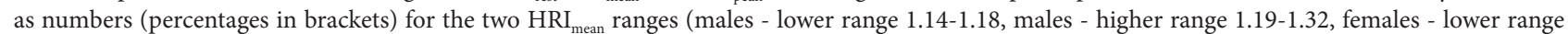
1.10-1.17 and females - higher range 1.18-1.34). 
beats. $\min ^{-1}(\mathrm{p}<0.001)$ is similar to that observed in previous studies $[18,19]$. Exercise participation had an even greater effect on $\mathrm{HR}_{\text {rest }}$ when comparing exercisers with nonexercisers, the difference being 11.0 beats $\cdot \mathrm{min}^{-1}(\mathrm{p}<0.001)$. The impact of smoking and non-exercise participation is shown in the representation of $\mathrm{HR}_{\text {rest }}$ as quartiles in Table 2 , with quartile 1 (predominantly non-smoking with a regular exercise habit) having a group mean $\mathrm{HR}_{\text {rest }}$ of 60.2 beats. $\mathrm{min}^{-1}$, compared with quartile 4 (predominantly smoking and non-exercise), which had a group mean $\mathrm{HR}_{\text {rest }}$ of 86.3 beats. $\mathrm{min}^{-1}$. Population studies have consistently shown that higher levels of CRF and physical activity are associated with lower rates of smoking [20,21]. Within this study, rates of smoking in exercising and non-exercising males were $27 \%$ and $67 \%$ respectively. A similar trend was noted with females, with smoking rates for exercising and non-exercising females being $22 \%$ and non-exercising $57 \%$ respectively.

The independent value of $\mathrm{HR}_{\text {rest }}$ as a prognostic variable is well established with lower levels of $\mathrm{HR}_{\text {rest }}$ being associated with reduced all cause and cardiovascular mortality [22]. The methods used for determining $\mathrm{HR}_{\text {rest }}$ are variable, two principal factors being position (supine, sitting or standing) and the time at rest before recording [22]. However, the $\mathrm{HR}_{\text {rest }}$ of male and female non-smoking subjects in this study is remarkably similar to Center of Disease Control (CDC) data (study males 69.2 beats. $\mathrm{min}^{-1}$, CDC males 68.5 beats. $\mathrm{min}^{-1}$, study females 72.7 beats. $\mathrm{min}^{-1}$, CDC females 72.5 beats $\cdot \mathrm{min}^{-1}$ ) [23]. $\mathrm{HR}_{\text {rest }}$ could have been measured independently of the HR histogram recorded data but the study design relied on the inclusion of a minimum 20-30 minute rest period (during refreshment and lunch breaks) for determination of $\mathrm{HR}_{\text {rest }}$. As $\mathrm{HR}_{\text {rest }}$ is a crucial measurement for determining HRI, it is highly desirable that its measurement is standardized.

Whilst the essential component of sedentary behaviour is that of prolonged sitting, the current consensus is that sedentary behaviour be defined by activities $<1.5$ METs [24]. Other studies e.g. Current Population Survey and the American Time Use Survey have used a higher cut-off point of 2 METs $[1,25]$. Within a sedentary occupation there will be components of prolonged sitting interspersed with periods of standing and walking. The sitting activity itself may entail various physical levels of upper limb activity. This variation in incidental activity associated with sedentary work will affect the average EI during a defined work period.

Whereas it is necessary to individually calibrate the HR$\mathrm{VO}_{2}$ relationship with exercise testing when using the $\mathrm{HR}_{\text {flex }}$ method [4], the HRI method does not have this requirement being independent of the various factors that influence the $\mathrm{HR}-\mathrm{VO}_{2}$ relationship [6]. $\mathrm{HR}_{\text {flex }}$ is frequently in the range of $8 \%-16 \%$ above $\mathrm{HR}_{\text {rest }}[26,27]$, i.e., equivalent to an HRI of 1.08-1.16, (estimated 1.5-2.0 METs), and that $\mathrm{HR}_{\text {flex }}$ increases significantly with ageing [28]. Studies that have used $\mathrm{HR}_{\text {flex }}$ as a cut-off point advocate that time spent below $\mathrm{HR}_{\mathrm{flex}}$ be considered as equal to resting metabolism i.e. $1 \mathrm{MET}$ $[28,29]$. For the 68 subjects within the combined sedentary and ambulant-sedentary categories, mean predicted MET levels for the entire work period ranged from 1.61 to 3.05 METs, with not one subject having a mean MET level of $<1.5$ METs. For the 25 subjects that had a HRI of $<1.16$ (approximating the upper limit of $\mathrm{HR}_{\mathrm{flex}}$ ), the estimated mean MET level was 1.84 METs, noticeably higher that what would have been accepted by the $\mathrm{HR}_{\text {flex }}$ method.

This study suggests that both smoking and exercise habit influence OPA particularly in sedentary occupations. Individuals with higher levels of incidental activity in the A +AS group as shown by a higher HRI ${ }_{\text {mean }}$ had significantly higher participation rates of LTPA (Table $3 \mathrm{~A}$ and $3 \mathrm{~B}$ ). In measuring sitting time and step counts of office workers, Clemes et al showed that office workers with lower sitting time had both higher step counts at work and on nonworkdays, suggesting higher levels of LTPA, a similar observation to this study [30]. The importance of identifying the more active sedentary worker is supported by the results a recent publication from the Maastricht study. Reallocation of 30 mins of sedentary time per day to standing or stepping was significantly associated with 7-25\% lower odds for the metabolic syndrome and 6-21\% lower odds for type 2 diabetes [31]. In our study, a trend towards a lower BMI was noted in both males and females in the more active ambulant and ambulant-sedentary groups, with these subjects having higher rates of LTPA and lower rates of smoking. Whether

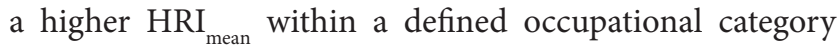
is associated with increased work productivity is a matter of conjecture. However, a known consequence of smoking and exercise habit is that higher rates of absenteeism have been observed with both smoking and lower levels of CRF $[32,33]$.

Three categories were used to define manual work (light, moderate and heavy). For these three categories, the estimated mean MET levels for males were 2.3, 2.4 and 3.1 respectively, and for females 2.2, 2.3 and 2.7 METs respectively. In using the commonly accepted international reference range for PA (sedentary 1.0-1.5 METs, light 1.62.9 METs, moderate 3.0-5.9 METs and heavy > 6 METs), 93 (86.1\%) of the manual 108 workers within the hospital would have been classed as 'light' OPA, the remaining 15 (18.9\%) of workers being within the 'moderate' OPA classification. Whilst this internationally accepted classification may be an appropriate expression of EI over a short period of continuous PA e.g. 15-60 minutes, it may be less appropriate for expressing the EI intensity over a prolonged period of discontinuous PA, with varying work intensity interspersed with rest breaks that are likely to occur during an 8-hour work schedule.

The utility of using a defined level of peak activity (as METs or alternatively as an $\mathrm{HRI}_{\text {peak }}$ ) is demonstrated in a study determining daily EE from ambulatory electrocardiographic monitoring of 843 patients at Beaumont Health in Royal Oak, Michigan. Mean and peak METs were estimated from the HRI equation [34]. Their study showed that peak activity greater than 5 METs was associated with significantly lower health cost (approximately 50\%) than with subjects having 
less than a 5 MET peak activity. With epidemiological studies it is clear that the method used to assess OPA is crucial, particularly if studies are to be compared, a comprehensive review of the strengths and limitations of PA assessment tools having been recently published by Ainsworth [35].

The rapid expansion of wearable technology has focussed on measurement of energy expenditure (EE). By using different sensors, commonly optical HR and motion sensors, proprietary algorithms utilize recorded data in conjunction with anthropometric variables to estimate EE. Currently, errors of measurement of EE with these devices are large (20-40\% error) when compared with the accepted comparators of indirect calorimetry or doubly labelled water [36]. However, the recent study by Colosio demonstrated that in using only HRI to determine EE, the results closely approximated those from equations validated by indirect calorimetry [7]. Data used in this study was acquired in 1983-84 using used a purpose-built microprocessorbased recorder to measure $\mathrm{HR}$ and generate and store HR histograms. Use of a histogram with a bin width of 5 beats. $\min ^{-1}$ was necessary to compress the data to fit into the miniscule available memory capacity at that time of only 256 bytes of data memory. Currently available HR recording devices have extremely large memory capacities (up to gigabytes) enabling recording of every heart beat over extended time periods (more than 24 hours). Our study suggests that the use of HR data alone, in the form of HRI may well provide a more accurate estimate of EE than that attained from proprietary algorithms incorporated in the presently available wearable devices. Data downloaded from these HR recording devices can be easily processed using commercially available spreadsheet programs enabling histogram construction and comprehensive data analysis. Time spent above defined MET thresholds can be determined and the extended recording time offered by these devices allows for separate interrogation of OPA and LTPA which assists in determining temporal trends of PA and health risk associated with both low and high levels of PA.

\section{CONCLUSIONS}

The results of this study suggest that smoking and CRF may influence the occupational behaviour of sedentary workers. By continuous recording of $\mathrm{HR}$ and the use of a HR histogram, $\mathrm{HR}$ indices derived from $\mathrm{HR}_{\text {rest }}, \mathrm{HR}_{\text {mean }}$ and $\mathrm{HR}_{\text {peak }}$ allow for estimates of EI during a period of OPA. The intrinsic value of the HRI is that it negates the effect of factors that may influence HR such as level of fitness, smoking habit and the effect of medication e.g. beta-blocker therapy. The observed levels of the three $\mathrm{HR}$ measurements $\left(\mathrm{HR}_{\text {rest }}, \mathrm{HR}_{\text {mean }}\right.$ and $\left.\mathrm{HR}_{\text {peak }}\right)$ and $\mathrm{HR}$ indices $\left(\mathrm{HRI}_{\text {mean }}\right.$ and $\left.\mathrm{HRI}_{\text {peak }}\right)$ have the potential to stratify health risk resulting from the effect of smoking and CRF on HR. This method appears to be particularly suited to evaluating sedentary occupations where the contribution of incidental activity to EE can be determined.

\section{ACKNOWLEDGEMENTS}

Associate Professor Kryss McKenna: BOccThy (Hons), $\mathrm{PhD}$ (deceased)

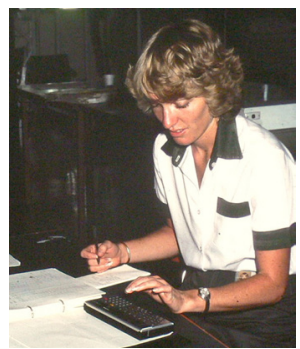

Dr Kryss McKenna (née Whittle) - Greenslopes Hospital 1984

(9 September 1962 - 15 April 2009)

This paper is written in memory of Dr Kryss McKenna who undertook the field work for this occupational study to complete the requirements of a Master thesis in 198384. She graduated with first class honours in Occupational Therapy in 1984 being awarded University of Queensland gold medal for her exceptional academic performance. She subsequently completed a PhD (University of Queensland) and had a distinguished career in both research and teaching as an associate professor within the Department of Occupational Therapy, University of Queensland. This study uses data collected by Dr Kryss McKenna from the Department of Occupational Therapy, University of Queensland as a requirement for her Master thesis to determine the EI of OPA of both sedentary and manual workers within a large metropolitan hospital. An outline of the study and its methods were published in The Occupational Therapy Journal of Research in 1987 [37].

The concepts used in this study remain uniquely original, the interpretation of the presented material having been influenced by the many articles published in relation to OPA in the intervening years.

The authors gratefully acknowledge the assistance offered by Professor Neil Oldridge (College of Health Sciences, University of Wisconsin-Milwaukee, Milwaukee, Wisconsin, United States of America) with data analysis during the drafting of this submission.

\section{Conflicts of Interest}

The authors declare no conflict of interest.

\section{REFERENCES}

1. Church TS, Thomas DM, Tudor-Locke C, et al. Trends over 5 decades in US occupation-related physical activity and their associations with obesity. PLoS One. 2011; 6(5):e19657.

2. Biswas A, Oh PI, Faulkner GE, et al. Sedentary time and its association with risk for disease incidence, mortality, and hospitalization in adults: a systematic review and 
meta-analysis. Ann Intern Med. 2015; 162(2):123-132.

3. Åstrand P-O. Textbook of work physiology: physiological bases of exercise. Human Kinetics; 2003.

4. Ceesay SM, Prentice AM, Day KC, et al. The use of heart rate monitoring in the estimation of energy expenditure: a validation study using indirect whole-body calorimetry. Br J Nutr. 1989; 61(02):175-186.

5. Ainsworth BE, Haskell WL, Herrmann SD, et al. 2011 Compendium of Physical Activities: a second update of codes and MET values. Med Sci Sports Exerc. 2011; 43(8):1575-1581.

6. Wicks JR, Oldridge NB, Nielsen LK, Vickers CE. HR Index-A Simple Method for the Prediction of Oxygen Uptake. Med Sci Sports Exerc. 2011; 43(10):2005-2012.

7. Colosio AL, Pogliaghi S. Quantification of energy expenditure of military loaded runs: what is the performance of laboratory-based equations when applied to the field environment? J R Army Med Corps. 2018:jramc-2017-000887.

8. Coyle E, Gonzalez-Alonso J. Cardiovascular drift during prolonged exercise: new perspectives. Exerc Sport Sci Rev. 2001; 29(2):88-92.

9. Rodahl, K. Occupational health conditions in extreme environments. Ann Occup Hyg. 2003; 47(3):241-252.

10. Abarca-Gómez L, Abdeen ZA, Hamid ZA, et al. Worldwide trends in body-mass index, underweight, overweight, and obesity from 1975 to 2016: a pooled analysis of 2416 population-based measurement studies in 128. 9 million children, adolescents, and adults. The Lancet. 2017; 390(10113):2627-2642.

11. Craig D. Microprocessor heart rate histogram recorder for ambulatory monitoring of daily physical activity. Med Biol Eng Comput. 1981; 19(3):367-369.

12. Andersen KL. The capacity of aerobic muscle metabolism as affected by habitual physical activity. Physical Activity and the Heart, edited by MJ Kar-Vonen, AJ Barry, Springfield, Ill, Charles C Thomas. 1967:5-20.

13. Naughton J, Hellerstein HK. Exercise testing and exercise training in coronary heart disease. Academic Press; 1973.

14. Hill D, White V, Gray N. Measures of tobacco smoking in Australia 1974-1986 by means of a standard method. Med J Aust. 1988; 149(1):10-12.

15. Åstrand I, Fugelli P, Karlsson C, Rodahl K, Vokac Z. Energy output and work stress in coastal fishing. Scand J Clin Lab Invest. 1973; 31(1):105-113.

16. Masironi R, Mansourian P. Determination of habitual physical activity by means of a portable RR interval distribution recorder. Bull World Health Organ. 1974; 51(3):291.

17. Mueller JK, Gossard D, Adams FR, et al. Assessment of prescribed increases in physical activity: application of a new method for microprocessor analysis of heart rate. Am J Cardiol. 1986; 57(6):441-445.

18. Papathanasiou G, Georgakopoulos D, Georgoudis G, Spyropoulos P, Perrea D, Evangelou A. Effects of chronic smoking on exercise tolerance and on heart rate-sys- tolic blood pressure product in young healthy adults. Eur J Cardiovasc Prev Rehabil. 2007; 14(5):646-652.

19. Perkins KA, Sexton JE, Epstein LH, et al. Acute thermogenic effects of nicotine combined with caffeine during light physical activity in male and female smokers. Am J Clin Nutr. 1994; 60(3):312-319.

20. Sandvik L, Erikssen J, Thaulow E, Erikssen G, Mundal $\mathrm{R}$, Rodahl K. Physical fitness as a predictor of mortality among healthy, middle-aged Norwegian men. N Engl J Med. 1993; 328(8):533-537.

21. Bernaards CM, Twisk J, Van Mechelen W, Snel J, Kemper H. A longitudinal study on smoking in relationship to fitness and heart rate response. Med Sci Sports Exerc. 2003; 35(5):793-800.

22. Zhang D, Shen X, Qi X. Resting heart rate and all-cause and cardiovascular mortality in the general population: a meta-analysis. Can Med Assoc J. 2015:cmaj. 150535.

23. Ostchega Y, Porter KS, Hughes J, Dillon CF, Nwankwo T. Resting pulse rate reference data for children, adolescents, and adults: United States, 1999-2008. US Department of Health and Human Services, Centers for Disease Control and Prevention, National Center for Health Statistics; 2011.

24. Tremblay MS, Colley RC, Saunders TJ, Healy GN, Owen N. Physiological and health implications of a sedentary lifestyle. Appl Physiol Nutr Metab. 2010; 35(6):725-740.

25. Tudor-Locke C, Ainsworth BE, Washington TL, Troiano R. Assigning metabolic equivalent values to the 2002 census occupational classification system. J Phys Act Health. 2011; 8(4):581.

26. Livingstone MB, Coward WA, Prentice AM, et al. Daily energy expenditure in free-living children: comparison of heart-rate monitoring with the doubly labeled water (2H2(18)O) method. Am J Clin Nutr. 1992; 56(2):343352.

27. Panter-Brick C, Todd A, Baker R, Worthman C. Comparative study of flex heart rate in three samples of $\mathrm{Ne}$ pali boys. Am J Hum Biol. 1996; 8(5):653-660.

28. Ekelund U, Brage S, Besson H, Sharp S, Wareham NJ. Time spent being sedentary and weight gain in healthy adults: reverse or bidirectional causality? Am J Clin Nutr. 2008; 88(3):612-617.

29. Wareham NJ, Hennings SJ, Prentice AM, Day NE. Feasibility of heart-rate monitoring to estimate total level and pattern of energy expenditure in a population-based epidemiological study: the Ely Young Cohort Feasibility Study 1994-5. Br J Nutr. 1997; 78(06):889-900.

30. Clemes SA, Patel R, Mahon C, Griffiths PL. Sitting time and step counts in office workers. Occup Med. 2014; 64(3):188-192.

31. van der Berg JD, van der Velde J, de Waard E, et al. Replacement Effects of Sedentary Time on Metabolic Outcomes-The Maastricht Study. Med Sci Sports Exerc. 2017; (7):1352-1358.

32. Weng SF, Ali S, Leonardi-Bee J. Smoking and absence from work: Systematic review and meta-analysis of occupational studies. Addiction. 2013; 108(2):307-319. 
33. Lahti J, Lahelma E, Rahkonen O. Changes in leisure-time physical activity and subsequent sickness absence: a prospective cohort study among middle-aged employees. Prev Med. 2012; 55(6):618-622.

34. George J, Abdulla RK, Yeow R, et al. Daily Energy Expenditure and Its Relation to Health Care Costs in $\mathrm{Pa}$ tients Undergoing Ambulatory Electrocardiographic Monitoring. Am J Cardiol. 2017; 119(4):658-663.

35. Ainsworth B, Cahalin L, Buman M, Ross R. The current state of physical activity assessment tools. Prog Cardiovasc Dis. 2015; 57(4):387-395.

36. Bunn JA, Navalta JW, Fountaine CJ, Reece JD. Current State of Commercial Wearable Technology in Physical Activity Monitoring 2015-2017. International journal of Exercise Science. 2018; 11(7):503.

37. McKenna KT, Maas F. Mean and peak heart rate prediction using estimated energy costs of jobs. OTJR: Occupation, Participation and Health. 1987; 7(6):323-334. 